DOI: 10.21625/resourceedings.v2i3.635

\title{
Visual culture in the sacred spaces figurative representation. The Duccio di Buoninsegna's Majesty cycle of stories
}

\author{
Vincenzo Cirillo ${ }^{1}$ \\ ${ }^{1}$ Department of Architecture and Industrial Design, University of Campania Luigi Vanvitelli
}

Email:vincenzo.cirillo@unicampania.it

\begin{abstract}
Starting from the XIII century the figurative arts underwent a profound transformation. In fact, we can note the gradual passage of the use of mosaic to the pictorial representation on the table and then on the wall, initially used for the altar paintings and then in all the sacred works. The figurative arts begin to break away from a predominantly symbolic conception to arrive to a narrative communication. Therefore, one of the first elements of representative experimentation begins to be the architectural space (interior and/or exterior) where to set up scenes of a sacred nature. The present contribution offers the graphic analysis of the cycle of stories present on the back of the large table depicting the Majesty of Duccio di Buoninsegna (1255-1318) which constitutes the triumphal epilogue of the Siena artist itinerary.

The 'putting into shape' of any iconographic apparatus (pictorial, engraved or graphical) depends fundamentally on the point of view from which one chooses to represent it. The determination of the latter is a function of distance from the representation framework; the direction of observation of the observer's height with respect to the station plan. With respect to this assumption, the present paper examines both the similarities and the differences that distinguish themselves in the use of different geometrical representation modalities for the staging of different spatial configurations that extract or immerse the observer in the context. Furthermore, graphic artifices designed to resolve points of incongruity obtained by the incorrect application of such codified methodologies which only in the following centuries are identified.
\end{abstract}

The research has currently obtained the graphic analysis and the identification of the different methods of geometric representation.

(c) 2019 The Authors. Published by IEREK press. This is an open access article under the CC BY license (https://creativecommons.org/licenses/by/4.0/).

Keywords

Architectural and visual cultures; pictorial sacred space; points of view; geometrical representation methods; modeling.

\section{The representation of the space}

The concept of space, subject of speculative research from the earliest times, today takes on a different meaning from the past, having revealed the inadequacy of unique and absolute definitions, but rather the opportunity for different formulations, each more suited to a specific area disciplinary (Giordano, D’Acunto, 2017).

Even before the speculative research stimulated human thought towards a process of abstraction from sensitive data to make it aware of the non-corporeal existence of such an entity, the presence of space was felt by primitive minds at an unconscious level, as a concrete experience, linked, from daily needs, to occasional directional references. Even 
the character of measurability was not dissociated from the shape and appearance of objects, to assume the abstract character of pure extension, without privileged orientations. The first intuitions, therefore, were still bound to all those mystical-emotional components that characterized the relationship of man with the external world and whose events, frightening because not understood and not dominable, aroused a kind of fearful respect. Over the centuries artists have adopted different ways of representing reality, according to the needs of the society in which they lived and their conception of the world. The way of depicting space in works of art has therefore changed several times, following a path in which progress has alternated with returns to previous systems.

The choice by an artist or a civilization of a specific method of representation of space is decisive both for the symbolic aspects of the work of art, and for the expressive ones. In the most ancient civilizations and in the most archaic phases of art, frontal representation and topological representation of space generally prevailed. The frontal representation foresees the projection of the subjects on a vertical plane, without the minimum foreshortening. The figures generally reproduced in a frontal position are almost completely devoid of depth and therefore appear unrealistic, abstract. Often, to further accentuate the solemnity or detachment of these figures from the earthly world, the artists have associated symmetry to the front view. The topological representation, on the other hand, involves the representation of an object from different points of view, including for example the frontal, lateral and top view within a single image.

In the Middle Ages the depth of space was represented by various systems, including that based on the principle of the obliquity of planes. Thanks to these systems, later, in the early fifteenth century, the architect Filippo Brunelleschi arrived at the elaboration of the linear perspective: a very naturalistic method of representing space, which provides an image resembling the reality perceived by our eyes (De Rosa, 2000).

Within the spatial pictorial experimentation in the Middle Ages (specifically the sacred space) different expedients were used to give the latter a correct graphic representation. Late medieval artists had achieved a good maturity of spatial depth; they had also produced numerous works in which this depth is represented, but the theme of the 'sacred' was still very rooted and therefore the space still represented only a 'frame' to the characters and not yet a symbolic form capable of transmitting the highest meanings of the world through a certain structural similarity.

\section{Visual culture in the sacred spaces of Duccio di Buoninsegna and the geometrical representation of the space}

In the city of Siena from the second half of the thirteenth century a particular tendency of local painting manifested itself towards forms of chromatic-linear expression. In this period strong personalities of artists who, without detaching themselves from the taste of tradition, give life to a new and original language, more subject to the suggestions of the transalpine Gothic who inclined to the realistic forms of Giotto to which almost all the Italian art of the Three hundred. Its constant characteristics are the attenuation of the sensitive data and the subordination of the values of volume and space (fundamental in Giotto's art) to the linear and chromatic ones, in short, to the composition based on the rhythm of lines and colors, with effects essentially of surfaces typical of Byzantine and Gothic painting. However, as in medieval art, these elements no longer have an absolute value, but are assumed as a function of a new form of living and concrete expression, in which on the other hand it is sensitive, in spite of everything, and sometimes it must have been the spiritual and aesthetic contribution of the great Giotto's revolution. Compared to Florence, the city of Siena developed a pictorial school particularly rich in energies, which was less centralized on the figure of a master than the Florentine one and which contrasted the Giotto style with a more decidedly Gothic orientation, probably derived, at least in part, from northern Europe. The first teacher of the Siena's school, older than Giotto of about fifteen years and practically of the generation of Cimabue, Duccio di Buoninsegna (1255-1318?), had had a formation of Byzantine imprint, as evidenced by the Madonna Rucellai (Florence, Uffizi), painted for the Florentine Compagnia dei Laudesi in 1285. From this moment on, however, there is the taste of a softer line and a more refined colorism than that adopted in the same years by Cimabue, and which is not even typical of Byzantine ancestry. The masterpiece of the artist, the Maestà, destined for the high altar of the cathedral of Siena and completed in 1311, fully testifies to this evolution, since of the Byzantine origins it preserves nothing more than the abstract layout of some folds highlighted in gold, a scheme that the artist applied only in the figures of the divine characters (Fig. 1). The 
colors come to the refinement of the half-tones in a warm range that gives the scene a character of poetic unreality. At first glance, Duccio may appear very close to Giotto for his spatial conception, as he places his characters in a space box, whose structure is often clearly emphasized by architectural elements; nevertheless, the depth of the pictorial plane remains in him more suggestive than visual and the architectural forms present more often than not lender proportions which give them a sort of unreality, in an entirely mental and fantastic interpretation (Bellosi, 1998).

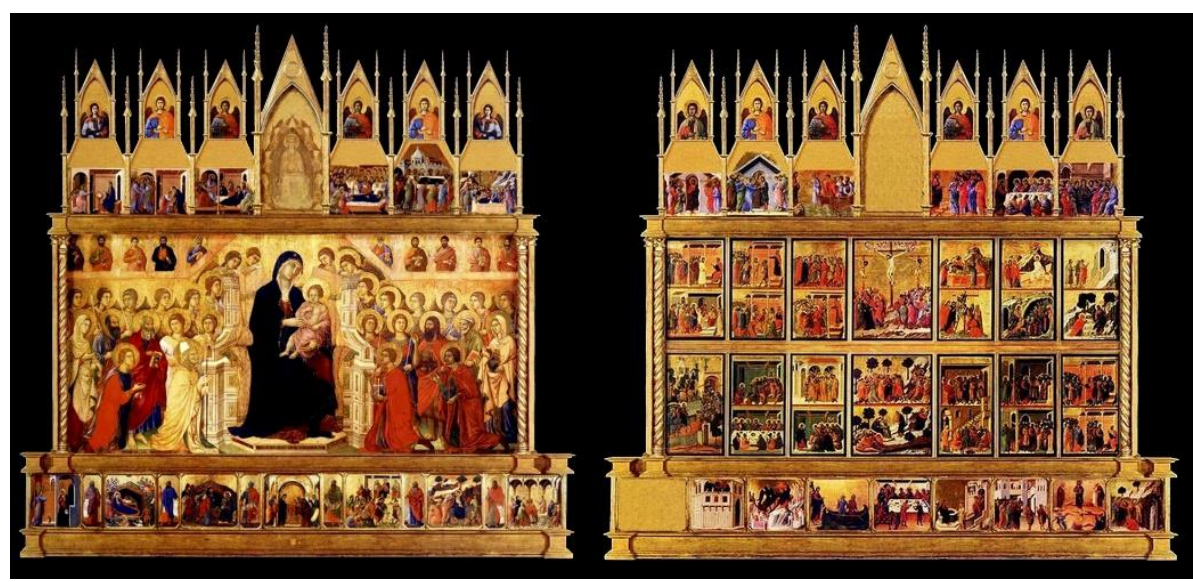

Figure 1. Duccio di Buoninsegna: Maestà (Majesty). Front view (on the left) and back view (on the right).

The monumental painting, now preserved (except for a few panels) in the room of the Museo dell'Opera del Duomo, bears on its front, gathered in a single large composition, the Madonna enthroned with the child between two tight bands of angels and saints in adoration. In the rear, divided into twenty-six compartments, episodes from the Passione di Cristo are illustrated, divided by a large median strip with a 'meander' that marks a necessary pause between the first scenes, in the lower order, and the latter, in higher order. The artist's intent appears to be to give the composition a twofold and equally effective impression of order and variety, of grandeur and minuteness, of solemnity and festivity, so as to strike the observer both with the effect of together as with the fineness of the detail (Donati, 1965).

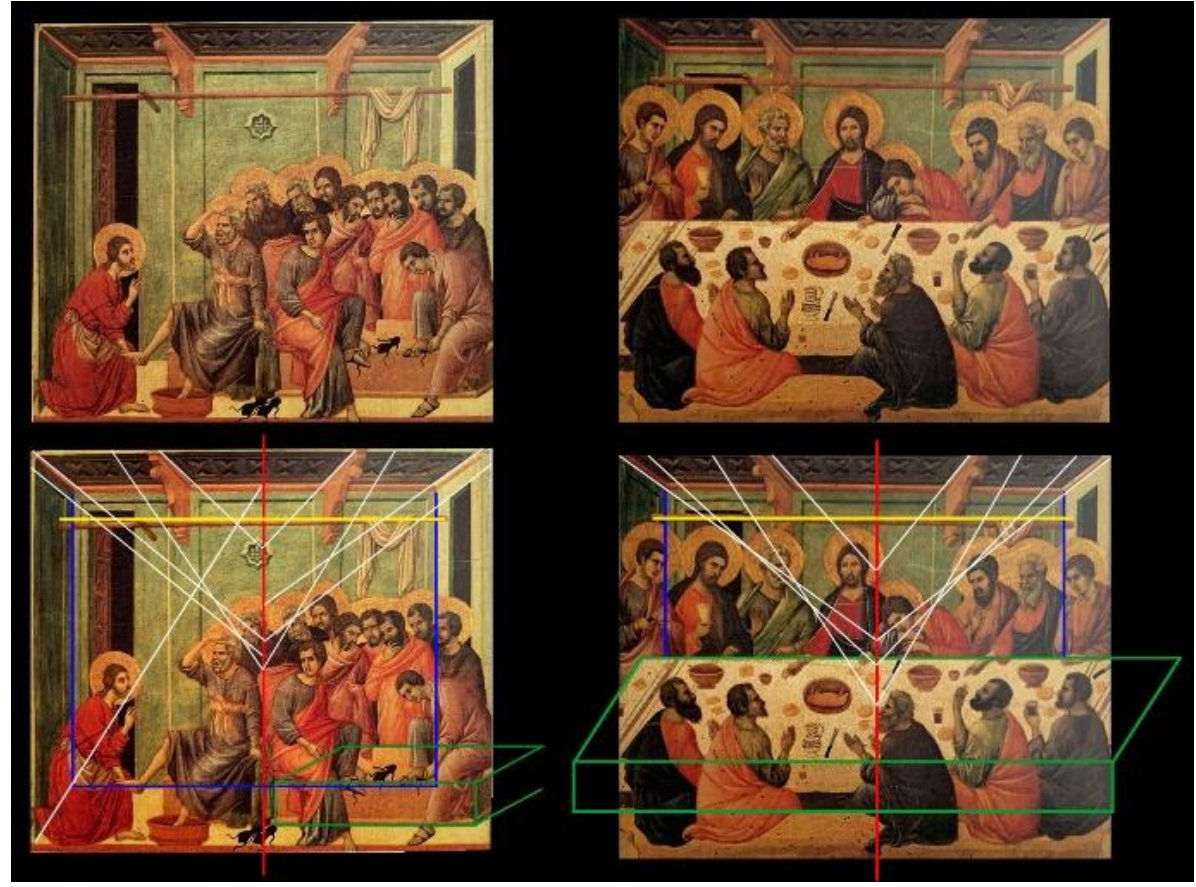

Figure 2. Graphical analisys of Lavanda dei Piedi e L'Ultima Cena with the use of integrated geometrical representation methods.

Within the specific disciplinary of the drawing a graphical analysis has been conducted here on the cycle of stories of Duccio's Maestà which presents different geometric systems used in the 'putting into form' of the stories and the choice of the 'point of view' from which observe it (De Rosa et al, 2000). Generally, the 'point of view' is determined in function of various principles: of the infinite distance or finite from the framework of representation, ie the plane 
on which the image of reality is projected; of the direction of observation of what is represented with respect to it; of the height of the observer with respect to the station plane in the case of a finite distance (Giordano et al, 2015). All these elements, combined together in different ways, determine a multiplicity of points of view from which to observe the same subject and, therefore, produces the construction of different images such as to completely abstract from the visual perception of the real by discharging it or in two-dimensional views (double orthogonal projections) or alluding to the three-dimensionality according to 'points of view' which extract the observer from the context that is being enslaved (method of parallel or cylindrical projections: axonometric) or which introduce it (method of central or conical projections: perspectives) (Zerlenga , 2016).

Duccio represented the depth of the space of the scenes carefully describing the closed environment in which they take place. In fact, it succeeds in rendering the depth of the rooms (especially the closed ones) through the use of a pseudo-perspective: the axes of the ceilings and side walls converge towards a vertical axis in the center of the painting and try to reproduce what we see when we find ourselves in a closed space (Giordano et al, 2018). However, this solution is replicated within each scene, offering the viewer various points of view. Specifically, within a given scene, Duccio represents with a point of view from the bottom scenes of ceilings and roofs while the parts placed on the ground level are observed from a different point of view, a point of view from above. The latter, together with various elements such as tables and seats, are represented with an oblique pseudo-axonometry, also known as 'parallel perspective' because they keep the forms contained in one of the two vertical planes unchanged, favoring the return of the fronts.

Therefore, Duccio di Buoninsegna mainly uses geometric methods of representation integrated between them. All the stories placed in the back of the altarpiece of the Maestà are organized by pseudo-axonometric views with topographical-perceptive impact of the planimetric and elevation system, attributable to the geometric method of representing the oblique axonometry cavaliera or parallel perspective, integrated with views pseudo-perspectives with a strong perceptive impact in restoring the elevation, which can be traced back to the geometric method of representing perspective with the perceptive use of depth indicators. The same configuration also occurs for the 'staging' of the story entitled the Pact of Judas. The latter appears to be located in the lower area, to the left of the altarpiece, where the apostle Judas Iscariot is represented in the act of receiving the thirty coins from the high priests to deliver Jesus into their hands.

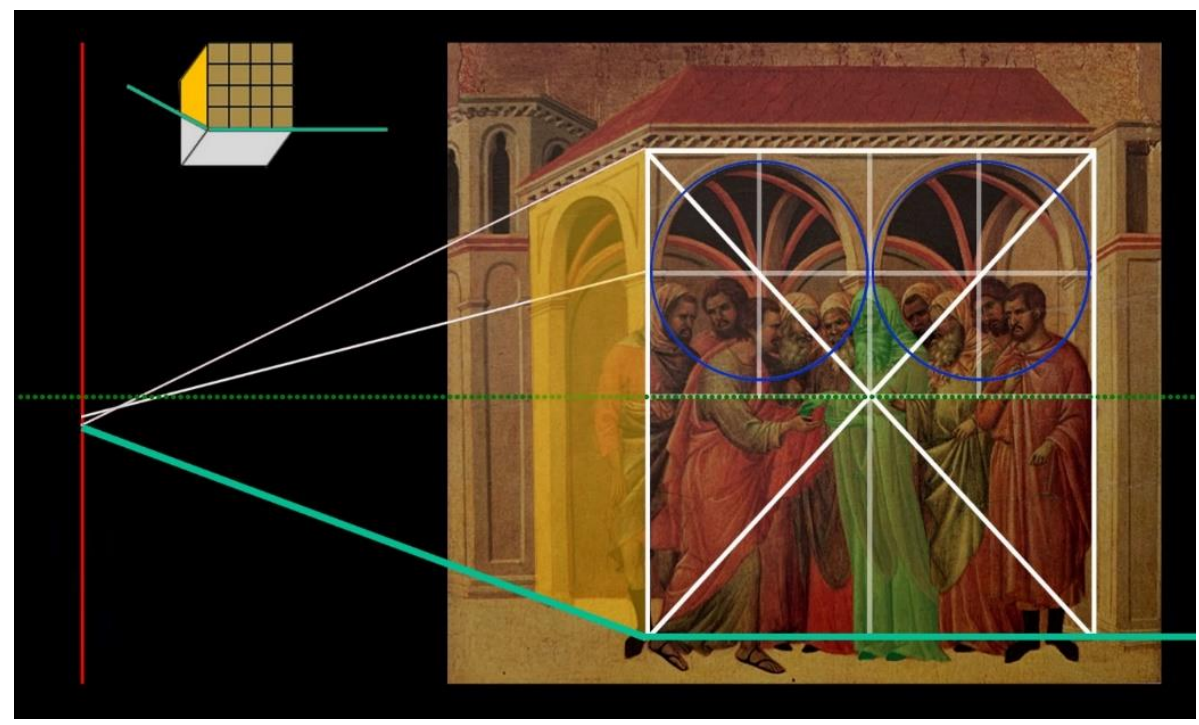

Figure 3. Graphical analysis of Patto di Giuda with the use of integrated geometrical representation methods.

For example, in the Lavanda dei piedi and Ultima Cena scenes (Fig. 2) the artist used the pseudo-perspective method with the central axis on which the various joints in the ceiling; the lower part, on the other hand, is represented by the pseudo-axonometric method. By virtue of the latter, the artist has given the sides of the table a different inclination than that of the ceiling, because, instead of making the two short sides converge towards the center, it has kept them parallel. Duccio has therefore used the principle of overlapping surfaces, chiaroscuro and obliquity to represent spatial depth, but for the latter he referred to two distinct systems. 
For this reason the table appears as an inclined plane and not as a horizontal plane with respect to the walls and ceiling beams. In this way he managed to represent both the apostles in the foreground and those on the other side of the table without overlapping each other, as would have happened only using the convergence of the lines towards the central axis. For the reasons mentioned above, that is the interest in the sacred theme and to ensure a better visualization and 'narration' of the scene Duccio has used this integration of representation methods to tell the episode more clearly. Finally, to these pseudo-perspective and pseudo-axonometric representations of the internal environments, Duccio also inserts depth indicators as surfaces of different colors to guarantee a sort of spatial depth (Cirillo, 2016).

Another example analyzed was the Pact of Judas scene. This latter takes place in a secluded place, enclosed in the bottom of the high walls of the Sanhedrin and by a deserted portico, whose cross vaults appear to be represented with a point of view from below. The main part of the representation, that is the one constituted by the group of characters, is framed inside a rectangle (Fig. 3) (D’Acunto, 2004). This latter incorporates the entire front of the portico and where the lower side houses the feet of Judas and the priests. The two openings of the portico divide the rectangle into two parts and in the central area appears the priest who leaves the coins to Judas. Furthermore, the diagonals of the rectangle intersect at a point located along the center line of the rectangle. The arches of the portico occupy respectively the two fourth upper parts of the rectangle even if their representation does not appear perfectly correct. As far as the geometric methods of representation are concerned, this narrative is organized by an oblique pseudoaxonometry cavalier with the prospect of the portico element placed in a plane parallel to the observer with a lower point of view than the view of the characters placed in the inside the scene. Focusing on a view from below, the observer admires the detail of the system turned on the porch but at the same time Duccio, to position the characters, must also insert a wide campaign plan. The correct graphic representation of this story, based on the representation of a pseudo-axonometric representation would imply that the latter was also observed from below. To ensure instead the inclusion of the characters Duccio inserts an oblique element (in flight) to place both the ground level and to ensure a certain spatial depth (Docci et al, 1992).

\section{Conclusions}

The present contribution wanted to highlight how in the Middle Ages the depth of space was represented by various systems, among which the one based on the principle of the obliquity of planes and by the use of integrated methods of geometric representation. The graphical analysis of the various tales of the altarpiece by Duccio di Buonisegna highlighted that the painter's aim was not to restore the image of sacred space with metric rigor, rather than to communicate the distinctive identity of the place appropriately using geometric methods of representation and, at the same time, derogating from them.

\section{References}

Bellosi, L. (1998). Duccio. La Maestà. Milano.

Cirillo, V. (2016). Modelli rappresentativi di città in "Il Regno di Napoli in Prospettiva" di Gio. Battista Pacichelli. In Capano et al, editor. Delli Aspetti De Paesi. Vecchi e nuovi media per l'immagine del paesaggio. Rappresentazione, memoria, conservazione. Napoli: Edizioni Circe.

D’Acunto, G. (2004). Geometrie segrete. L’architettura e le sue immagini. Padova: Il poligrafo.

De Rosa, A. (2000). La geometria nell'immagine. Storia dei metodi di rappresentazione. Dall'antichità al Medio Evo. Torino: UTET.

De Rosa, A. \& et al. (2000). La geometria nell'immagine. Storia dei metodi di rappresentazione. Torino: UTET.

De Vecchi, P. \& et al. (1999). I tempi dell'arte. Milano: Bompiani.

Docci \& et al. (1992). Scienza della rappresentazione. Fondamenti e applicazioni della geometria descrittiva. Roma: Carocci editore.

Donati, P.P. (1965). La Maestà di Duccio. Firenze: Sansoni.

Giordano \& et al. (2015). "Punti di vista" dell'architettura dipinta: l'opera di Arcangelo Guglielmelli a Santa Restituta.. In: Bartoli et al, editor. Le teorie, le tecniche e i repertori figurativi nella prospettiva d'architettura tra il '400 e il '700. Firenze:Firenze University Press, 437-446.

Giordano \& et al. (2017). Descrivere lo spazio. Dalla genesi geometrica alla rappresentazione delle superfici. Padova: Il Progetto.

Giordano \& et al. (2018). Prospettiva, Architettura, Deroga. Strumenti per la restituzionegrafica delle architetture dipinte nelle opere di Jacopo Tintoretto. In: Marsel, Grosso, editor. Titoretto e l'Aarchitettura. Venezia: Marsilio, 1, 150-152.

Zerlenga, O. (2016). Disegnare la città in "veduta”. Il manoscritto illustrato di Konrad Grünemberg. In Capano et al, editor. Delli Aspetti De Paesi. Vecchi e nuovi media per l'immagine del paesaggio. Rappresentazione, memoria, conservazione. Napoli: Edizioni Circe. 